\title{
Performance of compliant mechanisms applied to a modified shape accelerometer of single and double layer
}

\author{
M. Tecpoyotl-Torres ${ }^{1}$, R. Cabello-Ruiz ${ }^{2}$, P. Vargas-Chable ${ }^{3}$, J. G. Vera-Dimas ${ }^{4}$, A. Ocampo-Diaz \\ 1,3,5Research Institute of Basic and Applied Sciences-Research Center of Engineering and Applied Sciences \\ (IICBA-CIICAp), of Autonomous University of the State of Morelos (UAEM), Morelos, México \\ ${ }^{2}$ Technologic University Emiliano Zapata (UTEZ), Emiliano Zapata, Morelos, Mexico \\ ${ }^{4}$ Chemical Sciences and Engineering Faculty, of Autonomous University of the State of Morelos (UAEM), México
}

\begin{tabular}{l}
\hline \hline Article Info \\
\hline Article history: \\
Received Jan 1, 2019 \\
Revised May 11, 2019 \\
Accepted Jun 26, 2019
\end{tabular}

Keywords:

Accelerometer

$\mathrm{DaCM}$

Frequency

MEMS

Sensitivity

\begin{abstract}
Accelerometers are widely used in several mechanisms of high sensitivity. They are employed for example in tilt-control in spacecraft, inertial navigation, oil exploration, seismic monitoring, etc. In order to improve the sensitivity of the measurements, implementation of Displacement-amplifying Compliant Mechanisms (DaCMs) in a capacitive accelerometer have been reported in the literature. In this paper, a system composed of two elements; capacitive accelerometer with extended beams (CAEB) and a DaCM geometry, of single and souble layer, are analysed. Three materials were considered, in the case, for the second layer. The DaCM implementation improves the operation frequency and displacement sensitivity, under different proportions, at the same time. Furthermore, three sweeps were performed: a range of thickness from $25 \mu \mathrm{m}$ up to $30 \mu \mathrm{m}$ (to determine the appropriate silicon mass value, using SOI technology), a range of second layer thickness (to choose the more appropriate material and its thickness) and a range of gravity values (to determine the maximum normal stress in the beams, which defines the superior value of the g operation range). The in-plane mode (y-axis) was considered in all analysed cases. This characterization was developed using the Finite Element Method. Structural and modal analysis responses were under study.
\end{abstract}

Copyright $(0) 2019$ Institute of Advanced Engineering and Science. All rights reserved.

\section{Corresponding Author:}

Ramon Cabello-Ruiz,

Technologic University Emiliano Zapata,

Av. Universidad Tecnológica 1, Palo Escrito, 62765 Emiliano Zapata, Morelos, Mexico.

Email: ramon.cabello@uaem.mx

\section{INTRODUCTION}

Accelerometers measure the acceleration of an object by utilizing the classical Newtonian Law of Forces, where forces of the same magnitude will be generated in the opposite direction of the applied force. This force is normally detected by a movable part in the accelerometer and is translated into electrical signal using various electrical principles for further processing and data extraction [1]. These measurements are performed in one, two or three orthogonal axes. The acceleration measurements are typically used to calculate in-plane velocity and position, inclination, tilt or orientation in two or three dimensions with respect to the acceleration of gravity (g, equivalent to $9.81 \mathrm{~m} / \mathrm{s}^{2}$ ), as well as to measure vibration and impact [1-3]. The first batch-fabricatable accelerometer was reported in 1979 [4]. It was capable of measuring accelerations from 0.001 to $50 \mathrm{~g}$ over a $100 \mathrm{~Hz}$ bandwidth. Since 1990, accelerometers are commercialized and widely used in the automobile industries for triggering air-bag system in convertibles [1]. They have seen significant success in a large spectrum of applications, ranging from the automotive control and safety systems, consumer electronics for mobile, gaming, wearable and healthcare devices, and also in industrial, 
geophysical, and military/aero sectors [2, 5-9]. Capacitance accelerometers may be more suitable for some applications like automotive crash detection and air-bag deployment (high $\mathrm{g}$ force, such as 50g) [2]. Combination of desirable features like small size, low power dissipation, high sensitivity and low cost are nearly always needed for many of their applications [2]. Part of their research is focused on the optimization of the devices sensitivity, looking for a better efficiency. There are diverse types of accelerometers in the market, in [1] they are classified as: Capacitive, Piezoelectric, Piezoresistive, Hall Effect, Magneto resistive, Heat Transfer, Optical, and Tunnelling. Several materials have been studied to provide some advantages in the fabrication or in the response of accelerometers, as in [10]. A study of a controllable aluminium doped zinc oxide (AZO) patterning by wet etching for MEMS applications is given in [11].

Other structures have been developed to increase the displacement obtained in several accelerometers, such as mechanical amplifier, which can transform the displacement applied to the input in an amplified version of it, obtained at the output of the system. Mechanical amplifiers can have very simple geometries, as lever devices [12-14]. More complex devices are also implemented, such as the Displacementamplifying Compliant Mechanism (DaCM) shown in [15]. DaCMs are compliant equivalent of displacementamplifying levers, but they do not transfer the entire energy available to them at the input to the output because some of it is stored as the elastic strain energy within the mechanism [16]. A DaCM is used in [17] to enhance both the sensitivity and bandwidth of in-plane capacitive micromachined accelerometer. The input of the $\mathrm{DaCM}$ is attached to the proof-mass, allowing to obtain amplification or gain of mechanical signals, due to the assembling of simple parts such as rigid beams connected by assembly bolts [18].

This paper is focused on capacitive accelerometers, which uses the change in capacitance as a mean for measuring the acceleration of an object. They consist of a moveable central proof mass which provides the necessary inertia for providing the acceleration force for measurement, a fixed capacitive electrode to form a capacitor with the moveable proof mass, an anchor for providing support and springs to provide the flexure of the proof mass. Structural supports of mass are called suspension beams.

The objectives of this work are, by means of simulation and using the in-plane mode:

a. Make variations in the thickness of the moveable central proof mass, made with a Silicon layer, from 25 to $30 \mu \mathrm{m}$ to observe the changes produced in $\boldsymbol{S}_{\boldsymbol{x}}$, and in the operation frequency for a single capacitive accelerometer with extended beams (CAEB) and for the arrangement CAEB-DaCM.

b. Analyse the change on the $S_{x}$ and operation frequency when a second layer made of Aluminium, Silicon Nitride or Copper (materials commonly used in MEMS fabrication) is deposited over a Silicon layer of thickness $t_{1}=25 \mu \mathrm{m}$ and to perform variations in the thicknesses of $t_{2}$, from 1 up to $5 \mu \mathrm{m}$.

c. Demonstrate that the implementation of double-layer DaCMs improves $\boldsymbol{S}_{\boldsymbol{x}}$ and operation frequency in the double-layer accelerometers, with the proposed materials.

d. Perform a sweep of gravity values to know the operating limit of double-layer CAEB and CAEB-DaCM. Extreme operating conditions were obtained using the analysis of stress.

\section{RESEARCH METHOD}

For the case of capacitive accelerometer, $S_{x}$, can be calculated from (1) [19]

$$
\boldsymbol{S}_{\boldsymbol{x}}=m \boldsymbol{a} / k
$$

where $m$ is the mass of the system, $\boldsymbol{a}$ is the acceleration, and $k$ is the stiffness or spring constant, given by:

$$
k=E t\left(w_{b} / l_{b}\right)^{3}
$$

where $E$ is the Young's modulus of material, $t, w_{b}$ and $l_{b}$ are the thickness, width and length of the suspension beams, respectively.

The accelerometer will have an adequate $\boldsymbol{S}_{\boldsymbol{x}}$ corresponding to each acceleration value, as long as no resonance frequencies are present. It is well known, that before any resonance frequency is generated, the device will operate in accordance with the design requirements. For this reason, it is recommended to design devices for high operating frequencies in order to avoid low resonance frequencies. Operation frequency can be calculated, by (3), [19].

$$
f=(1 / 2)\left(N E t w_{b}{ }^{3} / m l_{b}{ }^{3}\right)^{1 / 2}
$$

where $N$ is the number of suspension beams.

About the implemented devices, CAEB is depicted in Figure 1, its elements and dimensions, are given in Table 1. Table 2 shows the properties of Silicon and the additional layer materials. Results for 
Silicon CAEB of constant thickness, considering the in-plane mode and one $\boldsymbol{g}$ applied were published in [19]; they are used in this paper only for comparison purposes.

Table 1. CAEB dimensions values

\begin{tabular}{cccc}
\hline Element & Value $(\mathrm{mm})$ & Element & Value $(\mathrm{mm})$ \\
\hline Beam length, $\mathrm{L}_{\mathrm{b}}$ & 4.5 & Anchor length, $\mathrm{L}_{\mathrm{a}}$ & 0.01 \\
Beam width, $\mathrm{W}_{\mathrm{b}}$ & 0.025 & Reduced mass width, $\mathrm{W}_{\mathrm{r}}$ & 0.70 \\
Mass length, $\mathrm{L}_{\mathrm{m}}$ & 7 & Reduced mass length, $\mathrm{L}_{\mathrm{r}}$ & 2 \\
Mass width, $\mathrm{W}_{\mathrm{m}}$ & 5.55 & & \\
\hline
\end{tabular}

Table 2. Properties values

\begin{tabular}{ccccc}
\hline Properties & $\begin{array}{c}\text { Silicon } \\
(\text { Semiconductor })\end{array}$ & $\begin{array}{c}\text { Aluminium } \\
(\text { Metal })\end{array}$ & $\begin{array}{c}\text { Aluminium Nitride } \\
\text { (Piezo electric) }\end{array}$ & $\begin{array}{c}\text { Copper } \\
(\text { Metal })\end{array}$ \\
\hline Density, $\rho\left[\mathrm{kg} / \mathrm{m}^{3}\right]$ & 2330 & 2689 & 3260 & 8933 \\
Thermal Expansion Coefficient, & $2.6 \times 10^{-6}$ & $24 \times 10^{-6}$ & $3.3 \times 10^{-6}$ & $16.5 \times 10^{-6}$ \\
$\alpha\left[1 /{ }^{\circ} \mathrm{C}\right]$ & 131 & 65 & 280 & 120 \\
Young's modulus, $E[\mathrm{GPa}]$ & 0.33 & 0.33 & 0.32 & 0.34 \\
Poisson ratio [Dimension-less] & 250 & 140 & 120 & 270 \\
Tensile yield strength, $[\mathrm{MPa}]$ & & & & \\
\hline
\end{tabular}

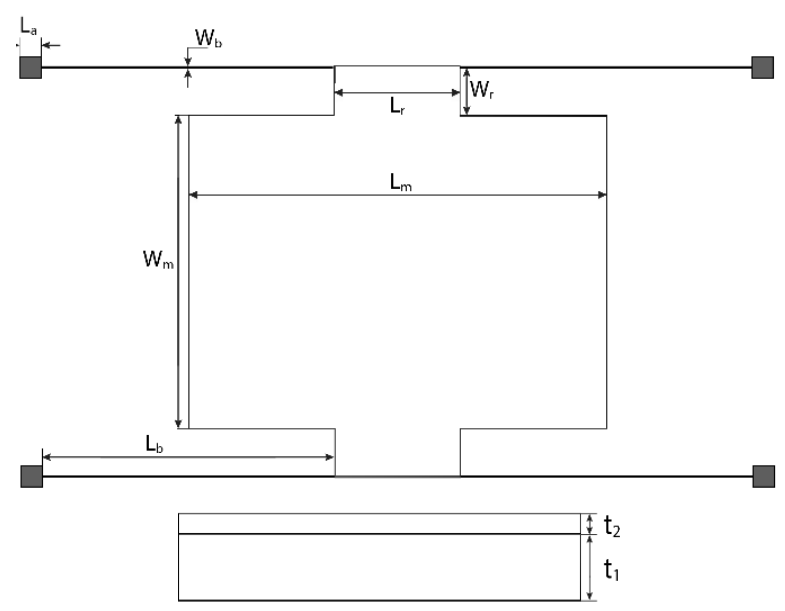

Figure 1. CAEB (a) elements and (b) transversal section, the thickness of the silicon layer and the additional layer (when it is applied) are $t_{1}$ and $t_{2}$, respectively

\section{RESULTS AND ANALYSIS}

In all simulated cases of subsections 3.1-3.3, one $\mathrm{g}$ is applied at $\mathrm{Y}$ axis direction.

\subsection{Displacement sensitivity and operating frequency of Silicon CAEB of different thickness}

In Table 3, calculated (with eq. (1-3)) and simulated values of parameters under analysis are shown. There are very small variations in both parameters, which can be considered as negligible. However, it is important to mention that there are very small percentages of variation between the theoretical and simulated results, of $0.46 \%$ and $0.15 \%$, for the displacement sensitivity and the operation, respectively. It can be said that the proposed equations and the boundary conditions (fixed anchors) established in the simulation of the devices are adequate, since they provide variations of less than $1 \%$, in both cases.

Table 3. Parameter values for CAEB made only with Silicon

\begin{tabular}{ccccc}
\hline \multirow{2}{*}{ Thickness $[\mu \mathrm{m}]$} & \multicolumn{2}{c}{ Calculated values } & \multicolumn{2}{c}{ Simulated values } \\
& $\boldsymbol{S}_{\boldsymbol{x}}[\mu \mathrm{m} / \mathrm{g}]$ & $f[\mathrm{~Hz}]$ & $\mathbf{S}_{\mathbf{x}}[\boldsymbol{\mu \mathrm { m } / \mathrm { g } ]}$ & $f[\mathrm{~Hz}]$ \\
\hline 25 & 10.74 & 152.06 & 10.79 & 151.82 \\
26 & 10.74 & 152.06 & 10.79 & 151.82 \\
27 & 10.74 & 152.06 & 10.78 & 151.94 \\
28 & 10.74 & 152.06 & 10.79 & 151.82 \\
29 & 10.74 & 152.06 & 10.79 & 151.82 \\
30 & 10.74 & 152.06 & 10.79 & 151.81 \\
\hline
\end{tabular}

Performance of compliant mechanisms applied to a modified shape accelerometer... (M. Tecpoyotl-Torres) 


\subsection{Displacement sensitivity and operating frequency of double layer CAEB}

In Table 4, parameter values for the CAEB are shown, when Silicon layer of $25 \mu \mathrm{m}$ thickness was used and another layer was added. In Figure 2, a representative case of $\boldsymbol{S}_{\boldsymbol{x}}$ and operating frequency of a double-layer CAEB is shown (the rest of cases are similar). Figures of Silicon CAEB were reported in [19]. From (1-3), $\boldsymbol{S}_{\boldsymbol{x}}$ and operation frequency have a direct and inversely proportional relationships to the mass of the system, respectively. This fact is also observed in the results shown in Table 4. For example, the structure made with additional Copper layer has higher $S_{x}(45.18 \mu \mathrm{m} / \mathrm{g})$. However; it is the one with the lowest operation frequency $(74.22 \mathrm{~Hz})$. The opposite case is shown by the structure with additional layer of Aluminium Nitride, which presents higher frequency $(187.6 \mathrm{~Hz})$, but lower $\boldsymbol{S}_{\boldsymbol{x}}$ value $(7.06 \mu \mathrm{m} / \mathrm{g})$.

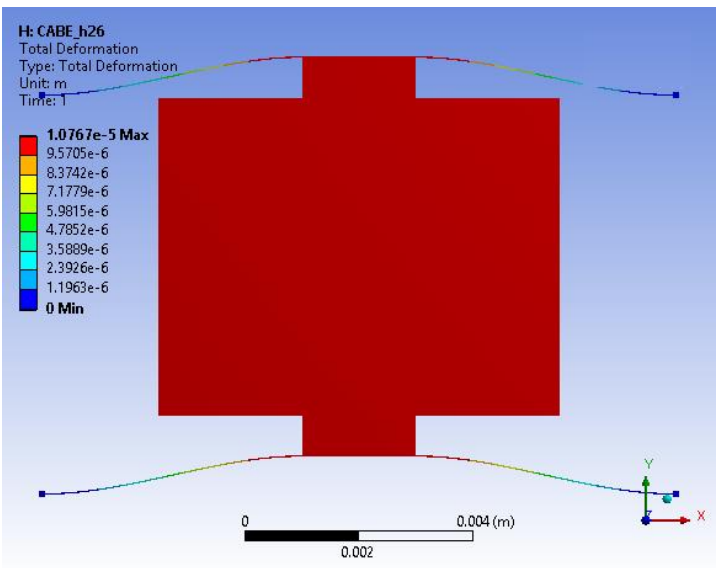

(a)

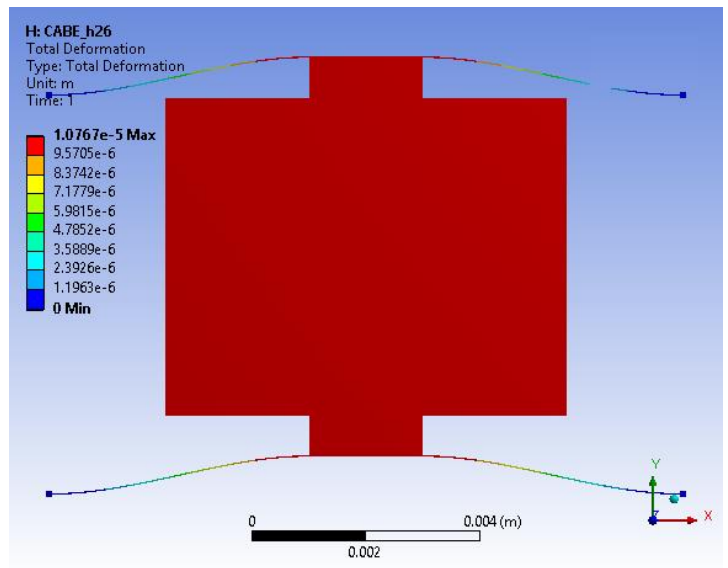

(b)

Figure 2. a) $\boldsymbol{S}_{x}$ and b) Operating frequency of Aluminium over Silicon

Table 4. Parameter values of CAEB of double layer $\left(t_{1}=25 \mu \mathrm{m}\right.$ of Silicon), obtained from simulation

\begin{tabular}{|c|c|c|c|c|c|c|}
\hline \multirow{2}{*}{$\begin{array}{c}\text { Additional layer } \\
\text { thickness }[\mu \mathrm{m}]\end{array}$} & \multicolumn{2}{|c|}{ Aluminium over Silicon } & \multicolumn{2}{|c|}{ Aluminium Nitride over Silicon } & \multicolumn{2}{|c|}{ Copper over Silicon } \\
\hline & $\mathbf{S}_{\mathbf{x}}[\mu \mathrm{m} / \mathrm{g}]$ & $f[\mathrm{~Hz}]$ & $\mathbf{S}_{\mathbf{x}}[\mu \mathrm{m} / \mathrm{g}]$ & $f[\mathrm{~Hz}]$ & $\mathbf{S}_{\mathbf{x}}[\mu \mathrm{m} / \mathrm{g}]$ & $f[\mathrm{~Hz}]$ \\
\hline 1 & 10.467 & 152.01 & 9.82 & 159.17 & 11.53 & 146.89 \\
\hline 2 & 10.771 & 151.97 & 9.67 & 160.68 & 12.44 & 141.41 \\
\hline 3 & 11.012 & 150.29 & 9.49 & 161.89 & 13.44 & 135.99 \\
\hline 4 & 11.224 & 148.89 & 9.29 & 163.59 & 14.35 & 131.63 \\
\hline 5 & 11.436 & 147.47 & 9.12 & 165.06 & 15.20 & 127.87 \\
\hline
\end{tabular}

\subsection{Displacement sensitivity and operating frequency of double layer CAEB-DaCM.}

For the CAEB structure made only with Silicon, the implementation of a DaCM improves both parameters simultaneously [19]. In this subsection, the effect of displacement amplifier on the CAEB of Silicon, with different thicknesses as shown in Table 5, and with double-layer also with different thickness as shown in Table 6. The shape of the displacement amplifier is similar to the given in [19]. For each case of double-layer CAEBs, the corresponding displacement amplifiers, have also an additional layer.

Table 5. Parameter values of CAEB-DaCM, made with Silicon of different thickness

\begin{tabular}{ccc}
\hline Thickness $[\mu \mathrm{m}]$ & $\boldsymbol{S}_{\boldsymbol{x}}[\boldsymbol{\mu \mathrm { m } / \mathrm { g } ]}$ & $f[\mathrm{~Hz}]$ \\
\hline 25 & 13.15 & 245.62 \\
26 & 13.14 & 245.66 \\
27 & 13.14 & 245.72 \\
28 & 13.15 & 245.63 \\
29 & 13.14 & 245.76 \\
30 & 13.15 & 2456.62 \\
\hline
\end{tabular}


Table 6. Parameter values of double layer CAEB-DaCM. Silicon layer has $t_{1}=25 \mu \mathrm{m}$

\begin{tabular}{|c|c|c|c|c|c|c|}
\hline \multirow{2}{*}{$\begin{array}{l}\text { Second layer } \\
\text { thickness }[\mu \mathrm{m}]\end{array}$} & \multicolumn{2}{|c|}{ Aluminium over Silicon } & \multicolumn{2}{|c|}{ Aluminium Nitride over Silicon } & \multicolumn{2}{|c|}{ Copper over Silicon } \\
\hline & $S_{x}[\mu \mathrm{m} / \mathrm{g}]$ & $f[\mathrm{~Hz}]$ & $S_{x}[\mu \mathrm{m} / \mathrm{g}]$ & $f[\mathrm{~Hz}]$ & $S_{x}[\mu \mathrm{m} / \mathrm{g}]$ & $f[\mathrm{~Hz}]$ \\
\hline 1 & 12.22 & 254.8 & 12.85 & 257.34 & 12.9 & 247.85 \\
\hline 2 & 13.52 & 242.69 & 12.08 & 257 & 15.59 & 226.22 \\
\hline 3 & 13.93 & 238.84 & 11.89 & 258.73 & 16.97 & 216.49 \\
\hline 4 & 14.27 & 235.89 & 11.77 & 259.84 & 18.25 & 208.69 \\
\hline 5 & 14.53 & 234.08 & 11.58 & 262.28 & 19.31 & 203.23 \\
\hline
\end{tabular}

In Figure 3, a representative case of the behaviour of the displacement sensitivity and the operating frequency of double layer CAEB-DaCM, are shown. Silicon case was previously reported [19]. Width of CAEB was reduced at one half of the original size, shown in Figure 1, in order to obtain lower mass to improve the operation frequency, since the implementation of the DaCM will improve $\boldsymbol{S}_{\boldsymbol{x}}$. The total length of displacement amplifier is $11 \mathrm{~mm}$ and its width is $3.5 \mathrm{~mm}$.

Differences in the parameter values for the case of variation parameters for Silicon CAEB-DaCM, as shown in Table 5, are negligible for the case of $\boldsymbol{S}_{\boldsymbol{x}}$ and slight for operation frequency, when additional layer has different thickness as shown in Table 6. From Table 6, although the increment occurs in both parameter values, it is much higher in the case of the operation frequency, compared to the case of single CAEB structure response. Table 7 shows the percentages of improvement in operation frequency, from $61.6 \%$ (for Aluminium Nitride over Silicon) up to $70 \%$ (for Aluminium over Silicon). While, $\boldsymbol{S}_{\boldsymbol{x}}$ shows improvements from 13.56 up to $30.87 \mu \mathrm{m} / \mathrm{g}$. In both cases, a second layer thickness of $1 \mu \mathrm{m}$ was considered.

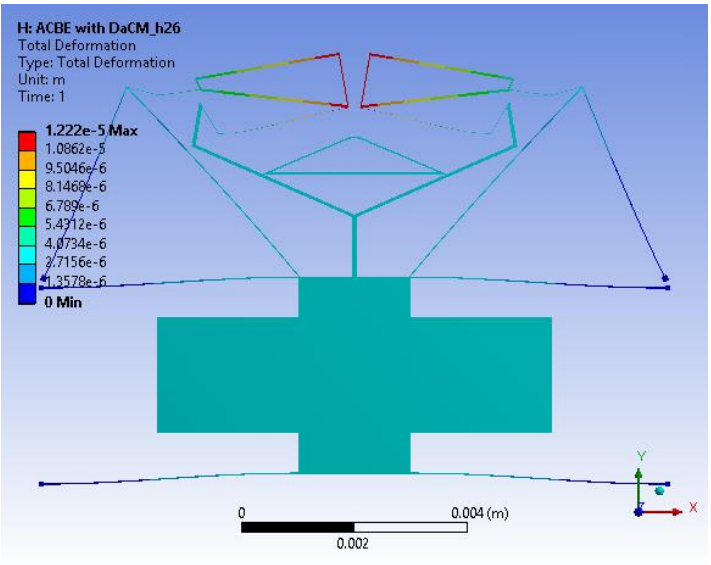

(a)

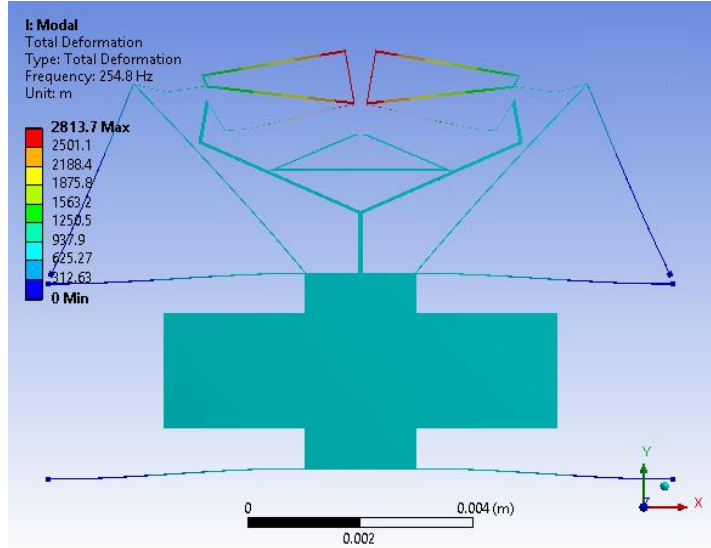

(b)

Figure 3. a) $S_{x}$ and b) Operating frequency of double layer CAEB-DaCM (Aluminium over Silicon)

Table 7. Percentage of improvement for CAEB-DaCM, compared to single CAEB response

\begin{tabular}{ccc}
\hline Material & Improvement of $\boldsymbol{S}_{\boldsymbol{x}}, \%$ & Improvement of $f, \%$ \\
\hline Silicon & 21.87 & 61.78 \\
Aluminium over Silicon & 13.56 & 70 \\
Aluminium Nitride over Silicon & 30.8 & 61.6 \\
Copper over Silicon & 11.88 & 68.7 \\
\hline
\end{tabular}

\subsection{Range of $g$ for single and double layer CAEB.}

The range of gravities for operation will be determined, verifying that the elastic limit in the normal effort is not exceeded in each case. Limit values of gravity are given in Tables 8 and 9 for CAEB made with Silicon and double layer, respectively. In all cases, the changes on the normal stress values are small for the considered thickness values. Gravity values are smaller in the case of double layer CAEB. In Figure 4, the zone with maximum Normal Stress for the case of CAEB of double layer made with Aluminium over Silicon is shown, as representative case. The zone of the higher normal stress for all these cases is located at the same extreme of the corresponding suspension beam. 
Table 8. Limit values of gravity for CAEB made with Silicon of different thickness

\begin{tabular}{ccc}
\hline Thickness $[\mu \mathrm{m}]$ & Gravity $[g]$ & Normal Stress, $[\mathrm{MPa}]$ \\
\hline 25 & 49 & 249.04 \\
26 & 48 & 244.85 \\
27 & 48 & 246.2 \\
28 & 49 & 248.92 \\
29 & 49 & 248.6 \\
30 & 48 & 247.73 \\
\hline
\end{tabular}

Table 9. Limit values of gravity for CAEB of double layer $\left(t_{1}=25 \mu \mathrm{m}\right)$

\begin{tabular}{|c|c|c|c|c|c|c|}
\hline \multirow{2}{*}{$\begin{array}{l}\text { Additional layer } \\
\text { thickness }[\mu \mathrm{m}]\end{array}$} & \multicolumn{2}{|c|}{ Aluminium over Silicon } & \multicolumn{2}{|c|}{ Aluminium Nitride over Silicon } & \multicolumn{2}{|c|}{ Copper over Silicon } \\
\hline & Gravity $[\mathrm{g}]$ & Normal Stress [MPa] & Gravity $[\mathrm{g}]$ & Normal Stress [MPa] & Gravity $[\mathrm{g}]$ & Normal Stress [MPa] \\
\hline 1 & 23 & 135.4 & 16 & 114.25 & 12 & 234.63 \\
\hline 2 & 23 & 136.15 & 16 & 114.86 & 12 & 235.91 \\
\hline 4 & 23 & 134.67 & 16 & 113.61 & 12 & 233.33 \\
\hline 5 & 23 & 136.99 & 16 & 115.6 & 12 & 237.28 \\
\hline
\end{tabular}

\subsection{Range of $g$ for CAEB with DaCM}

The limit values of gravity are shown in Tables 10 and 11, for CAEB-DaCM Silicon and double layer structures. It is remarkable for the cases with additional layers, under a not linear variations. Again, gravity values for double layer CAEB-DaCM are considerably reduced, comparing with the implementation only with Silicon, except for the case of Copper over Silicon, with $t_{2}=1$ um. Figure 5 shows the maximum normal stress zone, for a representative system made with Aluminium over Silicon (all cases have similar zone location).

Table 10. Limit values of gravity for CAEB-DaCM made with Silicon with different thickness

\begin{tabular}{ccc}
\hline Thickness $[\mu \mathrm{m}]$ & Gravity $[g]$ & Normal Stress $[\mathrm{MPa}]$ \\
\hline 25 & 100 & 247.6 \\
26 & 102 & 248.9 \\
27 & 101 & 248.8 \\
28 & 104 & 247.2 \\
29 & 105 & 249.02 \\
30 & 103 & 249.3 \\
\hline
\end{tabular}

Table 11. Limit values of gravity for double layer CAEB-DaCM $\left(\mathrm{t}_{1}=25 \mu \mathrm{m}\right)$

\begin{tabular}{ccccccc}
\hline $\begin{array}{c}\text { Second layer } \\
\text { thickness }[\mu \mathrm{m}]\end{array}$ & \multicolumn{2}{c}{ Aluminium over Silicon } & \multicolumn{2}{c}{ Aluminium Nitride over Silicon } & \multicolumn{2}{c}{ Copper over Silicon } \\
Gravity $[\mathrm{g}]$ & Normal Stress [MPa] & Gravity [g] & Normal Stress [MPa] & Gravity [g] & Normal Stress [MPa] \\
\hline 1 & 61 & 137.5 & 21 & 119.04 & 102 & 246.8 \\
2 & 42 & 137.1 & 16 & 112.7 & 70 & 245.8 \\
3 & 49 & 135.3 & 22 & 116.4 & 68 & 247.5 \\
4 & 49 & 135.3 & 24 & 116.6 & 56 & 246.5 \\
5 & 42 & 137.4 & 21 & 115.07 & 247.1 \\
\hline
\end{tabular}

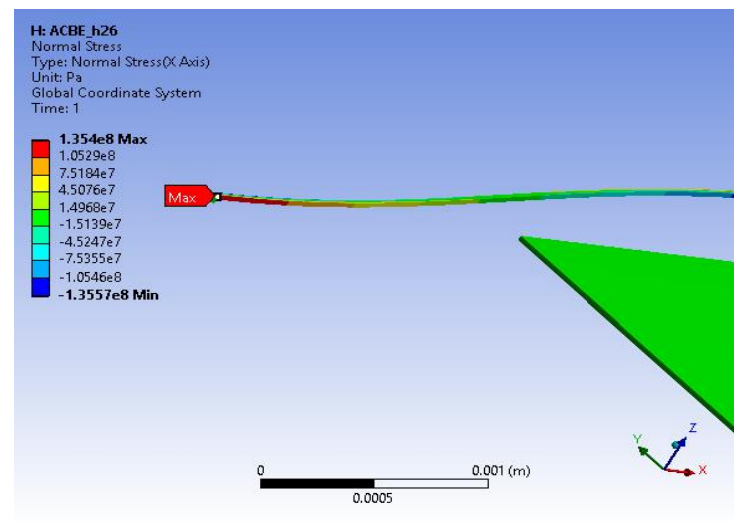

Figure 4. Normal Stress of CAEB of Aluminium over Silicon

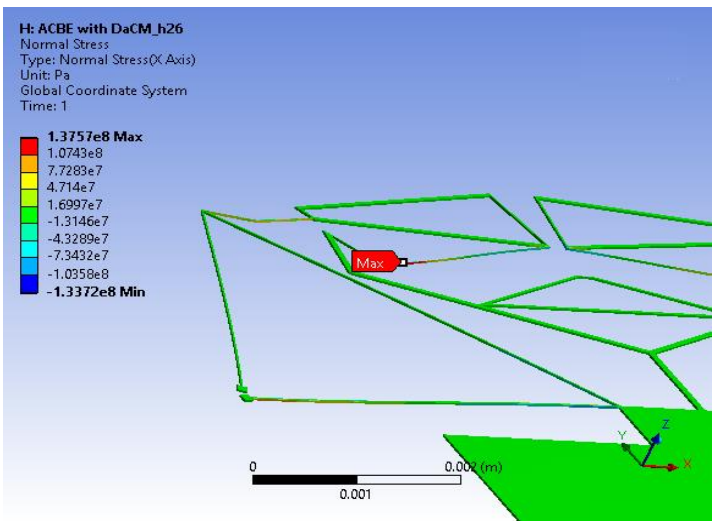

Figure 5. Normal Stress of CAEB-DaCM of Aluminium over Silicon 


\section{CONCLUSION}

For Silicon $C A E B$ : Values of $\boldsymbol{S}_{\boldsymbol{x}}$ and operation frequency show very small changes for different thickness $(25$ to $30 \mu \mathrm{m})$. Very small percentages of variation between the theoretical and simulated results, of $0.46 \%$ and $0.15 \%$, were obtained for $S_{x}$ and operation frequency, respectively.

For two layer CAEB: $S_{x}$ and operation frequency, have a direct and inversely proportional relationships to the proof mass, respectively, as for case of the previous case, in accordance to Equations (1-3). The lower values of $S_{x}(9.12 \mu \mathrm{m} / \mathrm{g})$ correspond to an additional layer of Aluminium Nitride (with $t_{2}$ of $5 \mu \mathrm{m}$ ) and the bigger one $\left(15.20 \mu \mathrm{m} / \mathrm{g}\right.$ ) corresponds to Cooper (with $\mathrm{t}_{2}=5 \mu \mathrm{m}$ ). The lower values of operation frequency $(127.87 \mathrm{~Hz})$ correspond for Copper (with $\mathrm{t}_{2}$ of $5 \mu \mathrm{m}$ ) and the bigger value $(165.06 \mathrm{~Hz})$ to Aluminium Nitride (with $\mathrm{t}_{2}=5 \mu \mathrm{m}$ ), for operation frequency. This value of $\boldsymbol{S}_{\boldsymbol{x}}$ exceeds the corresponding value of the Silicon CAEB by $40.87 \%$, while the bigger value of (Aluminium Nitride over Silicon) exceeds the same reference by $8.73 \%$.

For Silicon $C A E B-D a C M$ : A light increment in $\boldsymbol{S}_{\boldsymbol{x}}$, and a stronger one in operation frequency were obtained (13.15 $\mu \mathrm{m} / \mathrm{g}$ and $245.62 \mathrm{~Hz}$, equivalent to $21.87 \%$ and $61.78 \%$, respectively), compared to the Silicon CAEB parameter values without displacement amplifier.

CAEB-DaCM with additional Copper layer: It has higher $\boldsymbol{S}_{\boldsymbol{x}}(19.31 \mu \mathrm{m} / \mathrm{g})$. However, it is the one with the lowest operation frequency $(203.23 \mathrm{~Hz})$. The opposite case is presented by the structure with additional layer of Aluminium Nitride, which presents higher frequency $(262.28 \mathrm{~Hz})$, but lower $\boldsymbol{S}_{\boldsymbol{x}}$ $(11.58 \mu \mathrm{m} / \mathrm{g})$.

Gravities' swept applied to single and double-layer CAEB accelerometers: the effect of their thickness was not relevant, in each case. But, the range is considerably reduced for the double layer cases, in comparison with the single layer CAEB, especially for Copper over Silicon (75\%). For Aluminium Nitride $\left(\mathrm{t}_{2}=1 \mu \mathrm{m}\right)$ over Silicon, the reduction is of $(66.66 \%)$.

Gravities' swept applied to CAEB-DaCMs systems: $g$ values are considerable reduced when a second layer is implemented. It was observed that different values of gravities produce maximum normal stress values, depending of its thickness value, under a nonlinear tendence.

Values of tensile yield strength are near for Silicon and Copper, but differences on the limit operation range of $g$ values for single and double layer (made with Copper) CAEB-DaCM are considerable, varying from $100 \mathrm{~g}$ (for $25 \mu \mathrm{m}$ ) up to $105 \mathrm{~g}$ (for $29 \mu \mathrm{m}$ ), for the Silicon case, and from $102 \mathrm{~g}$ (for $25 \mu \mathrm{m} / 1 \mu \mathrm{m}$ ) down to $56 \mathrm{~g}$ (for $25 \mu \mathrm{m} / 5 \mu \mathrm{m}$ ), for the double layer case, improving the double layer CAEB response. The lower value of $g$ corresponds to the case of additional layer of Aluminium Nitride over Silicon with a thickness ratio of $25 \mu \mathrm{m} / 2 \mu \mathrm{m}$, of only $16 \mathrm{~g}$. CAEB-DaCM of the analysed cases could be used for different applications, in accordance to the requirements of displacement sensitivity, operation frequency or acceleration range.

\section{ACKNOWLEDGEMENTS}

M. Tecpoyotl-Torres, P. Vargas-Chable and J. G. Vera-Dimas thank to PRODEP and also to CONACyT for its support under grant A1-S-33433, "Proyecto Apoyado por el Fondo Sectorial de Investigación para la Educación". A. Ocampo-Diaz express her sincere thanks to CONACyT for the scholarship with grant reference 555954.

\section{REFERENCES}

[1] Y. Chin, J. Hasliona, and A. Nurul, "Classification on MEMS Accelerometer and Device Application", Proceedings of the Second International Conference on Technological Advances in Electrical, Electronics and Computer Engineering (TAEECE2014), Kuala Lumpur, Malaysi, pp. 215-225, March 2014.

[2] J. Fennelly, S. Ding, J. Newton and Y. Zhao, "Thermal MEMS Accelerometers Fit Many Applications," SENSOR MAGAZIN, vol 18, pp. 18-20, 2012.

[3] D. Mizell, "Using Gravity to Estimate Accelerometer Orientation", Proceedings of the Seventh IEEE International Symposium on Wearable Computers (ISWC'03), New York, USA, pp. 252-253, October 2003 DOI: 10.1109/ISWC.2003.1241424.

[4] R. L. Michelle and B. James Angell, "A batch-fabricated Silicon accelerometer", IEEE Transactions on Electron Devices, voil 26, (12), pp. 1911-1917, 1979.

[5] C. C. Yang and Y. L. Hsu, "A Review of Accelerometry-Based Wearable Motion Detectors for Physical Activity Monitoring," Sensors, vol 10, pp. 7772-7788, 2010, ISSN 1424-8220, DOI: 10.3390/s10080777.

[6] G. Ciuti, L. Ricotti, A. Menciassi and P. Dario, "MEMS Sensor Technologies for Human Centered Applications in Healthcare, Physical Activities, Safety and Environmental Sensing," A Review on Research Activities in Italy. Sensors, vol 15, pp. 6441-6468, 2015, DOI: 10.3390/s150306441.

[7] G. Lammel, "The Future of Mems Sensors In Our Connected World," Proceedings of MEMS 2015, Estoril, Portugal, pp. 61-64, January 2015, DOI: 10.1109/MEMSYS.2015.7050886. 
[8] X. Zou and A. A. Seshia, "A High-Resolution Resonant Mems Accelerometer," Proceedings of Transducers 2015, Anchorage, Alaska, USA, pp. 1247-1250, June 2015.

[9] A. Albarbar and S.H. Teay, "Chapter 2. MEMS Accelerometers: Testing and Practical Approach for Smart Sensing and Machinery Diagnostics," Advanced Mechatronics and MEMS Devices II, Microsystems and Nanosystems', D. Zhang, B. Wei, eds., pp.19-40, 2017, DOI 10.1007/978-3-319-32180-6_2.

[10] V. Seena, "A novel piezoresistive polymer nanocomposite MEMS accelerometer," Micromech. Microeng, vol 27, 9pp, 2016 DOI:10.1088/0960-1317/27/1/015014.

[11] M, Ralib, A. Nordin and N. Malik, "A study on controllable aluminum doped zinc oxide patterning by chemical etching for MEMS application," Microsyst Technol, vol 23, pp. 3851-3862, 2017, DOI 10.1007/s00542-015-2783-1.

[12] I. Zeimpekis, I. Sari and M. Kraft, "Characterization of a mechanical motion amplifier applied to a MEMS accelerometer," Microelectromech. Syst., vol 21, pp. 1032-1042, 2012, DOI: 10.1109/JMEMS.2012.2196491.

[13] C. Pedersen and A. Seshia, "On the optimization of compliant force amplifier mechanisms for surface micromachined resonant accelerometers," Micromech. Microeng, vol 14, pp. 1281-1293, 2004 DOI: 10.1088/0960-1317/14/10/001.

[14] X. Su and H. Yang, "Two-stage compliant micro-leverage mechanism optimization in a resonant accelerometer," Struct. Multidisciplinary Optim, vol 22, pp. 328-336, 2001, DOI: 10.1007/s00158-001-0153-3.

[15] G. Krishnan and G. K. Ananthasuresh, "A systematic method for the objective evaluation and selection of compliant displacement amplifying mechanisms for sensor applications," J. Mech. Des., vol 130, (10), pp. 2008, 102304:1-102304:9.

[16] G. Krishnan.: "Displacement-amplifying compliant mechanisms for sensor applications," (Master of Science (Engineering) thesis. Department of Mechanical Engineering Indian Institute of Science, 2006).

[17] K. Sambuddha and G. K. Ananthasuresh, "Improving the Sensitivity and Bandwidth of In-Plane Capacitive Microaccelerometers Using Compliant Mechanical Amplifiers," Microelectromechanical Systems, vol 23, pp. 871-887, 2014 DOI: 10.1109/JMEMS.2014.2300231.

[18] H. D. Kennedy-Cabrera, J. Hernandez-Torres, A. L. Herrera-May, J. Mireles Jr Garcia, and A. Sauceda-Carvajal, "Fabricación y caracterización de un amplificador mecánico flexible," Revista Mexicana de Física, vol 60, pp. 282-289, 2014.

[19] R. Cabello-Ruiz, M. Tecpoyotl-Torres, A. Torres-Jacome, V. Grimalsky, J. G. Vera-Dimas, and P. Vargas-Chable, "A Novel Displacement-amplifying Compliant Mechanism Implemented on a Modified Capacitive Accelerometer," International Journal of Electrical and Computer Engineering, vol 7, pp. 1858-1866, 2017 DOI: $10.11591 /$ ijece.v7i4

\section{BIOGRAPHIES OF AUTHORS}

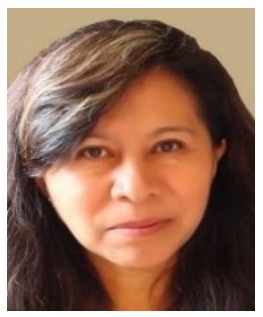

Margarita Tecpoyotl Torres received the Mathematician degree and was graduated as Electronic Engineer from the University of Puebla, Mexico, in 1991 and 1993, respectively. She received the M.Sc. and Ph.D. degrees in Electronics from INAOE, México, in 1997 and 1999, respectively. She works, since 1999, at CIICAp of UAEM, Mexico, where is currently titular professor. She has been visiting research scientist in University of Bristol (2001), UK. She led the Winner team of Boot Camp, UAEM Potential, obtaining a scholarship from TECHBA for the Full Immersion program in Silicon Valley (2014). In 2015 she won the third place in the Royal Academy of Enginnering in the Leaders in Innovation Fellowships final pitch session, in UK. She has four patents titles. She is co-founder of INNTECVER. She holds the status of National Researcher (SNI), in Mexico since 1999.

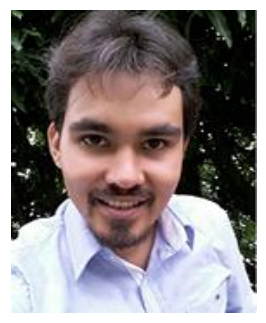

Ramon Cabello Ruiz received the degree of Mechanical Engineer (2010) from the Autonomous University of Morelos (UAEM), Mexico. He obtained the M.Sc. from Center for Applied Research in Engineering and Applied Sciences (CIICAp), Mexico, in 2012. Ramon Cabello is studying in a $\mathrm{PhD}$ Program of Engineering in CIICAp. He teachs at the Faculty of Chemical Sciences and Engineering at the UAEM.

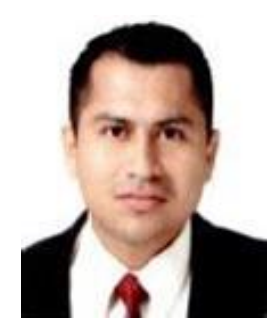

Pedro Vargas Chablé Received the B. Sc. Degree by the Autonomous University Juarez from Tabasco in 2008. From 2009 to 2012, he was Technical Specialist Assesment of Lighting Conditions and Non-Ionizing Radiation, NOM-025-STPS-2008 and NOM-013-STPS-1993 respectively, in Environmental Technology S.A of C.V. In 2014 he received the M.Sc. Degree at the Autonomous University of Morelos State (UAEM). He is a PhD student at the Research Center on Engineering and Applied Science (CIICAp) of the UAEM. His current research interest are FEA, microgripper, microactuators and VLSI. 


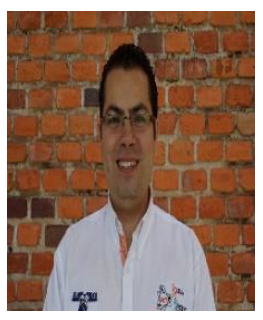

José Gerardo Vera is graduated from the Technological Institute of Morelia as Electronic Engineer. Currently, he is organizing member of ROPEC editions VII and VIII. He received the EGRETEC 2009 award as Young Graduated from the Graduated Association of the Technological Institute of Morelia. He got his Master degree with honors in the Research Center of Engineering and Applied Sciences (CIICAp) belonging to the Autonomous University of Morelos State (UAEM). He also got the PhD degree in Engineering and Applied Science in Electrical area. Gerardo Vera is part of the development of the curriculum of the Master in Commercialization of Innovative Knowledge and the Bachelor on Technology, both of CIICApUAEM. He was part of the winner team of the BootCamp 2013 organized by TechBA, also he is part of the winner team of a scholarship to be part of the program FULL IMMERSION in TechBA Silicon Valley.

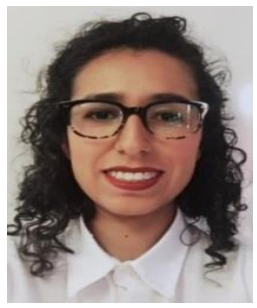

Ocampo-Diaz She studied Electrical Engineering at UAEM, in 2015 obtained the Master's Degree in Engineering and Applied Sciences at CIICAp,UAEM. 